\title{
Babesiosis as a potential threat for bovine production in China
}

\author{
Lan He $\mathrm{e}^{1,2^{*}} \mathbb{C}$, Reginaldo G. Bastos $2^{2}$, Yali Sun ${ }^{3}$, Guohua Hua ${ }^{4}$, Guiquan Guan ${ }^{5}$, Junlong Zhao ${ }^{1}$ and \\ Carlos E. Suarez ${ }^{2,6^{*}}$
}

\begin{abstract}
Babesiosis is a tick-borne disease with global impact caused by parasites of the phylum Apicomplexa, genus Babesia. Typically, acute bovine babesiosis (BB) is characterized by fever, anemia, hemoglobinuria, and high mortality. Surviving animals remain persistently infected and become reservoirs for parasite transmission. Bovids in China can be infected by one or more Babesia species endemic to the country, including B. bovis, B. bigemina, B. orientalis, B. ovata, B. major, B. motasi, B. U sp. Kashi and B. venatorum. The latter may pose a zoonotic risk. Occurrence of this wide diversity of Babesia species in China may be due to a combination of favorable ecological factors, such as the presence of multiple tick vectors, including Rhipicephalus and Hyalomma, the coexistence of susceptible bovid species, such as domestic cattle, yaks, and water buffalo, and the lack of efficient measures of tick control. BB is currently widespread in several regions of the country and a limiting factor for cattle production. While some areas appear to have enzootic stability, others have considerable cattle mortality. Research is needed to devise solutions to the challenges posed by uncontrolled BB. Critical research gaps include risk assessment for cattle residing in endemic areas, understanding factors involved in endemic stability, evaluation of parasite diversity and pathogenicity of regional Babesia species, and estimation of whether and how BB should be controlled in China. Research should allow the design of comprehensive interventions to improve cattle production, diminish the risk of human infections, and increase the availability of affordable animal protein for human consumption in China and worldwide. In this review, we describe the current state of BB with reference to the diversity of hosts, vectors, and parasite species in China. We also discuss the unique risks and knowledge gaps that should be taken into consideration for future Babesia research and control strategies.
\end{abstract}

Keywords: Apicomplexa, Babesia spp., Bovine babesiosis, Tick-borne diseases, P. R. China, Chinese cattle industry

\section{Background}

Babesiosis is a public health threat to human, domestic, and wild animals worldwide, especially in tropical and subtropical regions. The disease is caused by tick-borne

\footnotetext{
*Correspondence: helan@mail.hzau.edu.cn; reginaldo_bastos@wsu.edu; carlos.suarez@usda.gov

${ }^{1}$ State Key Laboratory of Agricultural Microbiology, College of Veterinary Medicine, Huazhong Agricultural University, Wuhan 430070, Hubei, China ${ }^{2}$ Department of Veterinary Microbiology and Pathology, College of Veterinary Medicine, Washington State University, Pullman, WA 99164, USA

${ }^{6}$ Animal Disease Research Unit, United States Department of Agricultural - Agricultural Research Service, Pullman, WA 99164, USA

Full list of author information is available at the end of the article
}

apicomplexan parasites of the genus Babesia that invade erythrocytes in their vertebrate hosts. Bovine babesiosis (BB) is characterized by acute fulminant disease, typically in naïve cattle older than one year, and may result in either death or the development of persistent infection in animals that have recovered from the acute phase. Persistently infected animals become reservoirs for transmission by competent ticks. BB was first described in 1888 in Romania by Victor Babes as a disease caused by microorganisms residing inside of erythrocytes of cattle with hemoglobinuria [1]. At the time, the causative pathogen was initially named Haematococcus bovis, and later renamed Babesia bovis [2]. Since then, more than original author(s) and the source, provide a link to the Creative Commons licence, and indicate if changes were made. The images or other third party material in this article are included in the article's Creative Commons licence, unless indicated otherwise in a credit line to the material. If material is not included in the article's Creative Commons licence and your intended use is not permitted by statutory regulation or exceeds the permitted use, you will need to obtain permission directly from the copyright holder. To view a copy of this licence, visit http://creativecommons.org/licenses/by/4.0/. The Creative Commons Public Domain Dedication waiver (http://creativeco mmons.org/publicdomain/zero/1.0/) applies to the data made available in this article, unless otherwise stated in a credit line to the data. 
100 Babesia species have been identified, and cases of babesiosis have been reported worldwide in animals and humans. Many of these species infect cattle, including $B$. bovis, B. bigemina, $B$. orientalis, $B$. ovata, $B$. major, $B$. occultans, $B$. divergens, $B$. jakiwivi, and $B$. venatorum [3]. In addition, $\mathrm{BB}$ can also be caused by $B$. U sp. Kashi, a new species identified in cattle from China [4]. Despite the scarcity of information, it is estimated that BB has a major economic impact on milk and meat cattle industries in China, causing significant losses every year. This review is aimed at increasing awareness about the current state of BB in China, the complex lacework of hosts, vectors, and pathogens, and highlight potential risks and knowledge gaps that limit progress towards control of this disease.

\section{Cattle, water buffalo, and yaks in China}

China is one of the largest agricultural countries in the world and one of the largest markets for protein consumption. According to the United States Department of Agriculture (USDA) Foreign Agricultural Service, China is the largest beef producing country in Asia and the fourth largest in the world, behind only the USA, Brazil, and the European Union. Despite the market size and increased demand, the total cattle population in China has decreased over 40\% from 2000 to 2017, while the water buffalo (Bubalus bubalis) population has remained relatively stable since 2012 (http://www.fao.org/faostat/ en/\#data/QC). By the end of 2018 the estimated inventory of cattle (not including water buffalo) in the country was around 89.2 million (http://www.stats.gov.cn/tjsj), including 10.4 million dairy cattle (China Dairy Yearbook, 2018) and 66.2 million beef cattle (National Beef Cattle Improvement Center, 2020; https://nbcic.nwsuaf. edu.cn/cyzx/76c7c38da3034eac8c4df79759bbec0b.htm). The overall decrease in cattle population from 2000 to 2017 may be due to mechanization of agricultural processes, resulting in a sharp drop in the use of animals. However, beef and milk production in 2019 were 6.67 million and 32.01 million tons, respectively (http://www. stats.gov.cn/tisj/). Considering the population of $1.4 \mathrm{bil}$ lion people in China, the per capita beef and milk production was only $4.766 \mathrm{~kg} /$ person and $22.865 \mathrm{~kg} /$ person in 2019, respectively. This implies immediate potential for these industry sectors to grow, especially to meet the demand as the Chinese economy and population continues to increase.

The dairy cattle population is mainly distributed in northern and eastern China and relatively less in the southern and western areas. Beef cattle are mainly concentrated in the intensive cropping areas along the central plains of Shandong and Henan provinces and in the northeast provinces of Jilin and Liaoning provinces.
There are low densities of cattle in some southeastern provinces while in the more extensive grazing systems of the northwest large cattle herds are distributed over large distances. Beef cattle populations in the southwest cover diverse areas of intensive crop-cattle and grazing systems in mountainous areas.

It is recorded that $97.4 \%$ of the world water buffalo population is currently located in Asian countries and is the second largest resource of milk-yielding livestock in the world, contributing approximately $50 \%$ of Asian milk production [5]. The total number of water buffalo in China is approximately 27.1 million, which is the third numerous in the world, behind only India (114.2 million) and Pakistan (38.8 million) (FAOSTAT, 2018, http://www.fao.org/faostat/en/). The total stock of water buffalo is gradually increasing in recent decades due to economic development and the launch of water buffalo milk and meat industries in central and southern regions of China.

White yak is a rare and unique yak breed that only lives in Tianzhu Tibetan Autonomous County, Gansu province, China. These animals are an important source of food and hides, mainly for people who live in these areas. White yaks are raised in cold and harsh conditions, as the altitude of Tianzhu ranges from 2040 to $4874 \mathrm{~m}$ above sea level. The animals feed on natural pasture usually at the altitude of $3400 \mathrm{~m}$ above sea level with annual average temperature of $0.2-1.3{ }^{\circ} \mathrm{C}$. The total population of domestic yaks is estimated to be around 14 million in China [6] while the number of white yaks is only around 39,400 [7]. White yaks have a strong ability to adapt to ecological environments with low oxygen and are indispensable multipurpose livestock for people living in Tianzhu, as these animals supply meat, dairy products, and hides $[8,9]$. The complex interactions between water buffalo, white yaks, and additional breeds of bovids with Babesia spp. needs to be considered in order to better estimate the impact of $\mathrm{BB}$ on the milk and meat industry in China, and to design strategies for disease control.

In addition, the presence of native bovid species, such as yaks (Bos mutus and Bos grunniens for wild and domestic yaks, respectively), may play an important role in the dynamics of BB in China. A recent study showed that yaks might be at high risk for infestation with ticks competent for the transmission of Babesia spp. It has also been reported that $B$. bovis, B. bigemina, B. ovata, and $B$. venatorum are spreading in the white yak populations, which poses an additional threat to this already endangered bovine species $[3,9]$. Also, climate changes may broaden the habitat of ticks competent to transmit Babesia spp. therefore affecting the indigenous populations of white yaks. 


\section{Diversity of Babesia spp. infecting bovids in China: historical, climatic and geographic perspectives}

The earliest recorded case of a disease caused by intraerythrocytic protozoa affecting cattle in China may have occurred more than 100 years ago in Chifeng city, Inner Mongolia [10]. However, officially, the first case of BB was reported in 1974 with a B. bigemina outbreak in Fuzhou city, Fujian province [10]. Later in the same year, 10 of 20 cows died of piroplasmosis in Jinhua city, Zhejiang province. Around the same year, 90 cows imported from New Zealand were rapidly infested with ticks, and, as a result, 15 of them died with signs of BB within 10 days after exposure to the ticks [10]. After that episode, sporadic cases of BB were reported in 19 provinces between 1949 and 1989 [10]. It was also during this period that research on babesiosis was launched in China.

The geographical distribution of the multiple Babesia species detected in bovids in China is shown in Fig. 1, according to the epidemic data from 1947 up to the present day. The most widespread species in both cattle and water buffalo are B. bovis and B. bigemina [10-15] (Figs. 1 and 2). These parasites were first isolated and identified by Yang and Wang in 1964 in Guizhou province [10]. By that time, Rhipicephalus microplus was confirmed as the tick vector [16]. Babesia bovis and B. bigemina often coinfect cattle since they share $R$. microplus as their tick vector. Incidence of $B$. bigemina, which has been detected in 24 provinces and autonomous regions, is dependent on the distribution of $R$. microplus. However, B. bovis has only been reported in 21 provinces and autonomous regions [17]. This discrepancy may be due to the differences in the life cycle of B. bigemina and B. bovis. While $B$. bigemina can be transmitted by $R$. microplus larvae, nymphs, and adults, $B$. bovis is only transmitted by the tick larval stage [16]. In addition, the range of ticks that transmit $B$. bigemina is larger than those that transmit $B$. bovis [18]; however, in China, so far, the only competent tick species for B. bigemina identified is R. microplus [16]. Epidemiological studies have shown that the infection rates of B. bigemina and B. bovis are as high as $90 \%$ in some locations, especially in Hunan, Hubei, Yunnan, Guizhou, and Sichuan provinces [19]. An outbreak of $B$. bigemina was reported in yaks in 1989, where 309 animals died in the Sichuan province. The presence of $R$. microplus on the infected animals suggested the participation of this tick species in the outbreak $[12,13]$. Recent reports also identified B. bigemina [9] and B. bovis [15]

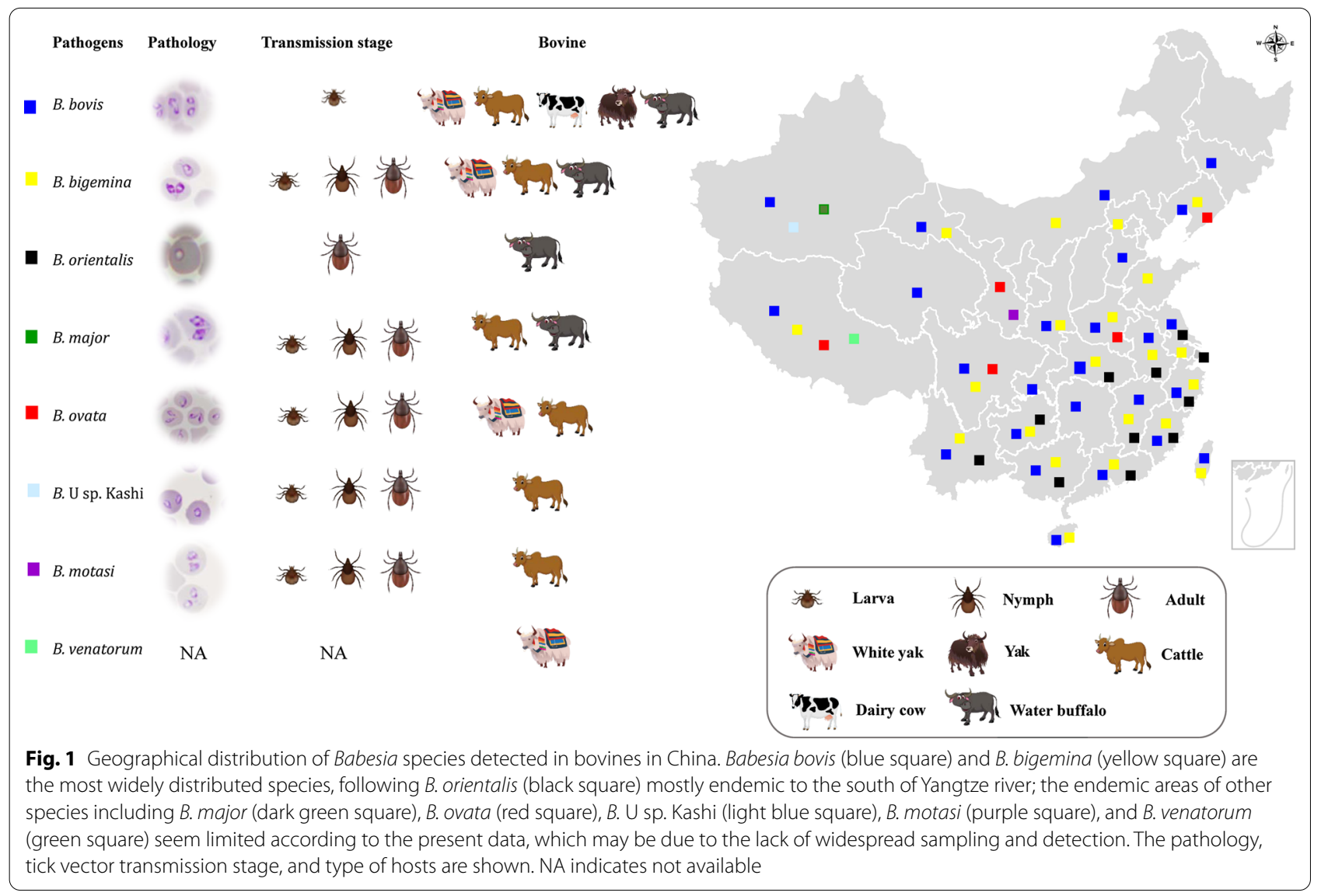



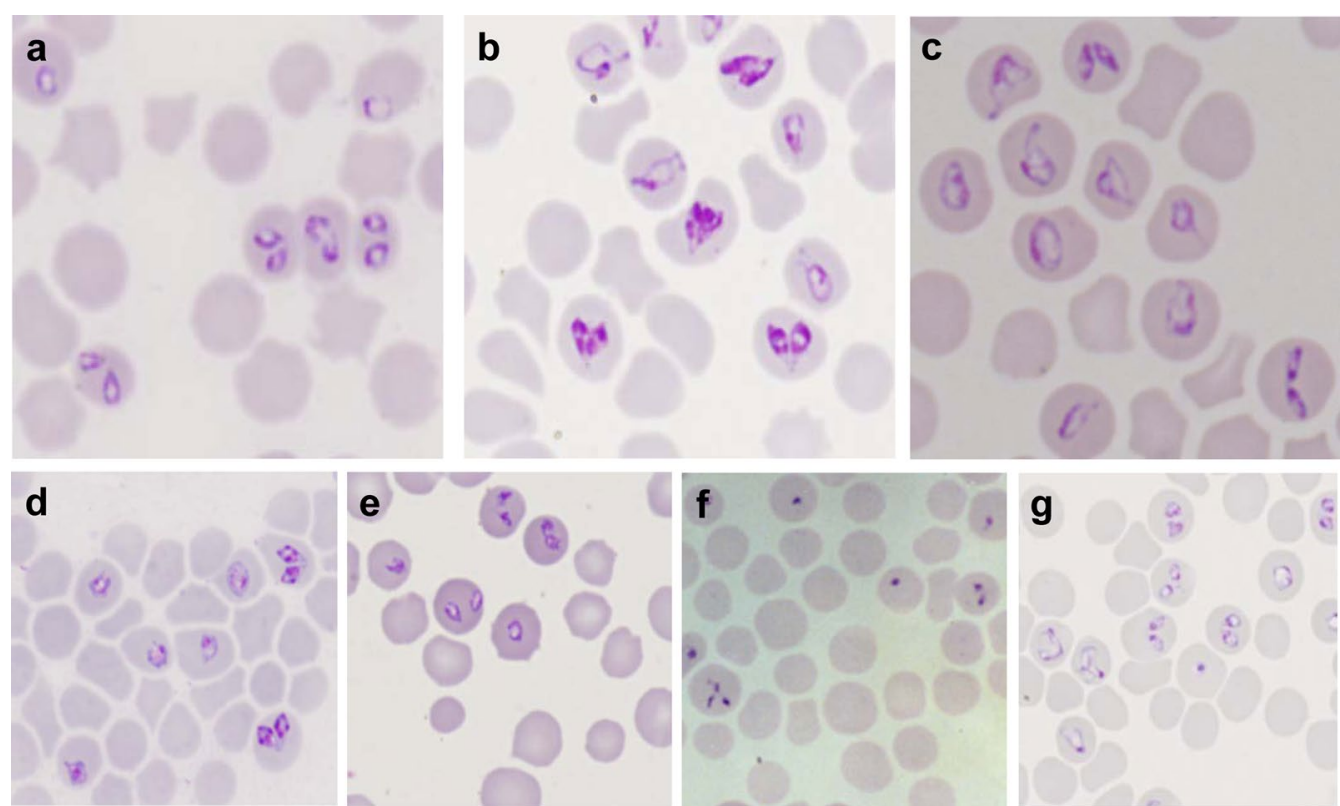

Fig. 2 Giemsa-stained thin blood smear of bovine Babesia spp. Intraerythrocytic forms of B. bovis (a), B. bigemina (b), B. ovata (Wenchuan isolate) (c), B. major (Yili isolate) (d), and B. U sp. Kashi (e) were obtained from experimentally splenectomized cattle. Intraerythrocytic forms of B. orientalis (f) were obtained from an experimentally splenectomized water buffalo and B. motasi $(\mathbf{g})$ from an experimentally infected sheep. Magnification $\times 1000$

infection in yaks and white yaks in the Gansu province, which poses an additional threat to this important bovine breed [3]. In contrast, $B$. orientalis, a relatively benign species that is present in central and south regions of China, has only been described in water buffalo, and apparently does not infect cattle or yaks [20]. Babesia orientalis is a small parasite (Fig. 2) that has currently been reported in 12 provinces in central and southern parts of China [20]. It was first reported in 1984 in water buffalo [20-22], and subsequently demonstrated that the parasite can only be transovarially transmitted by the adult stage of the three-host tick Rhipicephalus haemaphysaloides [23]. Earlier studies have mistakenly identified $B$. orientalis as $B$. bovis, and/or B. bigemina according to the pathogen's morphology inside erythrocytes [24]. After careful examination, the parasite was renamed as B. orientalis in 1997 according to the differences in host susceptibility, transmission vector competence, morphology, pathogenicity, and characterization of in vitro culture $[20,25,26]$. Babesia orientalis can only infect water buffalo, while in contrast, $B$. bovis and B. bigemina can infect a diversity of bovids, including Bos taurus, Bos indicus, Bos mutus, and Bubalus babalis. In addition, R. microplus, a competent vector for $B$. bovis and B. bigemina, is unable to transmit $B$. orientalis [27]. According to epidemiological investigations, $B$. orientalis was mainly restricted to the area located south of the Yangtze River but then it started spreading to the northern area of the river in 2009. This was probably due to the construction of several bridges and the transportation of water buffalo to both sides of the river [28].

Babesia major and B. ovata were initially isolated in Xinjiang and Henan provinces, respectively [29, 30]. These two Babesia species caused an academic argument about species identification and validation in China. In 1988, a Babesia species isolated from Haemaphysalis longicornis ticks collected in Lushi County, Henan Province was suspected to be $B$. ovata or B. major [29-31]. Later, the parasite was identified as $B$. ovata $[29,31]$. In order to investigate the distribution of this parasite, several isolates were obtained from different geographic regions, such as Zhangjiachuan (B. ovata Zhangjiachuan) and Ningxian (B. ovata Ningxian) county of Gansu and Wenchuan $[B$. ovata (Wenchuan isolate)] county of Sichuan province (Fig. 2) [32-34]. At the same time, an unidentified Babesia species was isolated from calves infested with adult Haemaphysalis punctata ticks collected from Yili county of Xinjiang Uygur Autonomous Region (Fig. 2). The parasite was initially characterized as $B$. major, but then renamed as B. major (Yili isolate) due to its vector tick [35]. Traditionally, discrimination between $B$. major and $B$. ovata is mainly based on the tick vectors involved [36, 37], considering that $B$. major is transmitted by $H$. punctata [38] while B. ovata is transmitted by H. longicornis [39]. Subsequently, Yin et al. [40] reported that $B$. major could be transmitted by both $H$. 
punctata and $H$. longicornis at larval, nymphal, and adult stages in experimental conditions. After that, the argument focused on whether these Babesia species should be classified into $B$. major or $B$. ovata considering that both species share many similarities in morphology and pathogenicity [29]. Recent phylogenetic analysis of $18 \mathrm{~S}$ rRNA gene and internal transcribed spacer region demonstrated that $B$. ovata Lushi, B. ovata Ningxian, B. ovata (Wenchuan isolate), and $B$. ovata Zhangjiachuan, which are all transmitted by $H$. longicornis, fall into one single clade, while B. major (Yili isolate), which is transmitted by $H$. punctata, falls into a separate clade [34, 41]. Both these Babesia species have low pathogenicity in intact calves, do not cause apparent clinical disease, and are not generally considered important pathogens, in comparison to B. bovis and B. bigemina [30, 31, 40]. Correlation with $B$. major and its vector tick only prevails in the northern regions of Xinjiang Uygur Autonomous Region while $B$. ovata is possibly widespread in China due to its ability to be transmitted by $H$. longiconrnis larvae, nymphs, and adults, which are distributed in most Chinese regions [42]. Babesia ovata was also recently identified in white yaks in the Gansu province [3].

Babesia U sp. Kashi is another recently identified species found to infect cattle in China (Fig. 2). In 2002, Luo et al. described an unidentified Babesia species that showed low virulence in calves and which was isolated from Hyalomma anatolicum collected from Kashi County of Xinjiang province. This newly isolated species was designated Babesia U sp. Kashi [4] and subsequent experiments showed that the parasite was transmitted by larval, nymphal, or adult stages of $H y$. anatolicum, $H y$. detritum, and Hy. rufipes Koch. Interestingly, Babesia U sp. Kashi was not transmitted by either $R$. microplus or $H$. longicornis [43]. Molecular phylogeny using the $18 \mathrm{~S}$ rRNA genes showed that Babesia U sp. Kashi is different from other Babesia species previously identified [44]. Additional genetic and molecular studies are needed to validate the Babesia $\mathrm{U}$ sp. Kashi as a new species and examine potential relatedness of this species with Babesia beliceri from Russia and B. occultans from South Africa, which are also transmitted by Hyalomma ticks [44-46].

Babesia motasi, which primarily infects sheep and goats (Fig. 2), was recently identified in cattle in the Gansu province, China [11]. In the 1980s, Chen [47] and Zhao et al. [48] first reported cases of ovine babesiosis in the Sichuan and Heilongjiang provinces, respectively. Considering that sheep were involved in these cases, the causative agent was mistakenly assumed to be B. ovis. In 1996, an outbreak of ovine babesiosis was reported in several herds of small-tailed han sheep imported from the Shandong province in Ningxian county of Gansu province. At the time, two ovine Babesia strains were isolated: a large Babesia highly virulent for sheep and goats, which was primarily designated as Babesia sp. or B. motasi, and Babesia sp. BQ1 (Ningxian), and a small Babesia with low virulence that was classified as $B$. ovis $[49,50]$. In addition, it was demonstrated that the larger form of the parasite was able to be transovarially transmitted by $H$. longicornis ticks [51]. To date, a total of six B. motasi-like isolates have been reported in sheep and goats, including Babesia sp. BQ1 (Lintan), Babesia sp. BQ1 (Ningxian), Babesia sp. (Liaoning), Babesia sp. (Tianzhu), Babesia sp. (Madang), and Babesia sp. (Hebei) [52, 53]. Some of these isolates, such as Babesia sp. BQ1 (Lintan), were able to be experimentally transmitted by both $H$. longicornis and $H$. qinghaiensis at larval, nymph, and adult stages $[54,55]$. In 2020, Sun et al. described the first report of B. motasi in cattle, showing $10 \%$ positive infection rate in Minqin city, Gansu province, China [11]. Unfortunately, at the time, no ticks were collected from infected cattle in that area. Considering the identification of $B$. motasi-like parasites in both cattle and small ruminants, it would be interesting to investigate the genetic homology of these isolates. Collectively, these results indicate that further studies are required to find out potential risks imposed by $B$. motasi to livestock in these affected areas in China.

Babesia venatorum (formerly Babesia sp. EU1) is a zoonotic parasite first reported in Italy and Austria in two splenectomized men [56], and also in deer and sheep [46, 57]. In 2014, Sun et al., reported the first B. venatorum case in China. An 8-year-old boy who lived in Pishan County, Xinjiang Autonomous Region was detected with a parasitemia of 5\% [58]. So far, 48 human cases have been reported in China [59], and have later been identified in white yaks from Tianzhu Tibetan Autonomous county, China, in 2017 [3]. A total of 409 samples were tested by nested PCR targeting the $18 \mathrm{~S}$ rRNA gene. Four samples were positive for $B$. venatorum based on the sequences. No tick vectors were collected from the infected white yaks; however, Ixodes ovatus ticks were collected from Tianzhu Tibetan Autonomous County. Vectors implicated in the transmission of B. venatorum are currently unknown. However, Ixodes persulcatus has been suggested as a competent vector for $B$. venatorum in Mongolia [60] and Heilongjiang province, China [59]; however, additional investigation is needed to test this hypothesis.

Babesia divergens is a well-known zoonotic species that infects bovines. This parasite can be transmitted by I. persulcatus, which is widespread in China. However, interestingly, $B$. divergens infections have been reported in humans and ovines, but not in bovines in China. Qi et al. [61] reported in 2011 the first $B$. divergens-infected human case in Shandong province, China. A total of 
377 human blood samples were analyzed and two were found positive for $B$. divergens $18 \mathrm{~S}$ rRNA, as confirmed by sequencing. Wang et al. [62] demonstrated a $1.3 \%$ (10/754) positive rate tested by $18 \mathrm{~S}$ rRNA PCR in human samples in the Gansu province, China. Ixodes persulcatus is a competent vector for $B$. divergens that is widespread in China [63]. Despite the concern of $B$. divergens as a zoonotic pathogen and that all cases involved humans, no data are available of the incidence of this parasite in bovines. Further studies are needed to investigate additional competent vectors and the impact of $B$. divergens in bovines from China, especially considering that $I$. ovatus is also a possible competent vector for this parasite in infected dogs from Japan [64]. Also, these investigations can potentially bring to light the implication of $B$. divergens for both human and animal health in China.

Babesia occultans is considered a benign species that primarily infects cattle and it was first described in South Africa in 1981 [46]. The first suspected report of B. occultans in China was in 2018, and also at that time, parasites were identified in Dermacentor nuttalli collected from sheep in Xinjiang Uygur Autonomous Region, China [65]. Unfortunately, blood samples of the infected sheep were not collected and tested, therefore, there was no confirmatory evidence of the presence of $B$. occultans in sheep in these areas. In 2019, Sun et al. [66] reported $B$. occultans in Hyalomma asiaticum collected from sheep in the Gansu province, China. Babesia occultans was speculated to be originally a parasite typically infecting African antelope, which can explain the presence of the parasite in ticks collected from co-grazing ovine.
Although potential competent vectors are widespread in China, B. occultans infection has not been identified in bovines and further epidemiological, genetic, and pathogenicity studies need to be performed on B. occultans in bovines to understand its prevalence in China.

Importantly, I. persulcatus, which is a competent vector for B. divergens, as well as D. nuttalli and Hy. asiaticum ticks, which are also vectors for B. occultans, are also widespread in China (Table 1). Considering this scenario, it is likely that both, $B$. divergens and $B$. occultans are already circulating among cattle in the country, posing additional risk for the cattle industry and human health. Therefore, confirmatory epidemiological studies should be conducted to evaluate the actual impact of $B$. divergens and $B$. occultans in bovines in the Chinese provinces.

As can be appreciated from the presented data, there is a large diversity of Babesia organisms circulating among distinct ticks and bovids in China, and as more research is performed, it is likely that other unknown species may be discovered in the future. Furthermore, it is interesting that some parasite species that are known to specifically infect certain hosts, such as $B$. motasi, a parasite that causes disease in sheep, were only identified infecting cattle in China [11]. This situation differs dramatically from other endemic countries, such as Australia, Brazil, Mexico, and Argentina, among other countries, where the diversity of Babesia spp. appears to be much more limited and usually restricted only to $B$. bovis and B. bigemina [67-70].

Table 1 Babesia species infect cattle and water buffalo in China

\begin{tabular}{|c|c|c|c|c|c|}
\hline Species & Size $(\mu \mathrm{m})$ & Pathogenicity & Host & Tick vector & References \\
\hline B. bovis & $2.0 \times 1.5$ & Severe & Cattle, water buffalo, yak, white yak & R. microplus, R. annulatus (N), R. geigyi (N) & {$[3,10,16,101]$} \\
\hline $\begin{array}{l}B . \\
\text { bigemina }\end{array}$ & $4.5 \times 2.0$ & $\begin{array}{l}\text { Moderately } \\
\text { severe }\end{array}$ & Cattle, water buffalo, white yak & $\begin{array}{l}\text { R. microplus, R. decoloratus (N), R. annulatus (N), } \\
\text { R. geigyi }(\mathrm{N}) \text {, R. evertsi }(\mathrm{N})\end{array}$ & {$[3,9,10,16,102]$} \\
\hline $\begin{array}{l}\text { B. orien- } \\
\text { talis }\end{array}$ & $\begin{array}{l}1.2- \\
1.5 \times 2.0-2.6\end{array}$ & Severe & Water buffalo & R. haemaphysaloides & {$[20,22,23,26]$} \\
\hline B. ovata & $3.2 \times 1.7$ & Benign & Cattle, white yak & H. longicornis & {$[3,29,31]$} \\
\hline B. major & $2.6-3.7 \times 1.5$ & Benign & Cattle, water buffalo & H. punctata & {$[34,41]$} \\
\hline $\begin{array}{l}\text { B. U sp. } \\
\text { Kashi }\end{array}$ & $\begin{array}{l}1.5- \\
5.0 \times 1.2-3.0\end{array}$ & Benign & Cattle & Hy. anatolicum & {$[4,44]$} \\
\hline B. motasi & $2.5-4.5$ long & $\begin{array}{l}\text { Moderately } \\
\text { severe }\end{array}$ & $\begin{array}{l}\text { Ovine } \\
\text { cattle }\end{array}$ & H. punctata, R. bursa & {$[11,47,48]$} \\
\hline $\begin{array}{l}\text { B. venato- } \\
\text { rum }\end{array}$ & Unknown & Unknown & White yak & I. persulcatus, I. ovatus & [3] \\
\hline $\begin{array}{l}\text { B. diver- } \\
\text { gens }^{\mathrm{a}}\end{array}$ & $1.5-2 \times 0.4$ & $\begin{array}{l}\text { Moderately } \\
\text { severe }\end{array}$ & Human, ovine & I. ricinus (N), I. persulcatus & {$[61,62]$} \\
\hline $\begin{array}{l}\text { B. occul- } \\
\text { tans }\end{array}$ & $2.9 \times 1.2$ & Benign & $\begin{array}{l}\text { No report in host, but detected in } \\
\text { ticks in China }\end{array}$ & D. nuttalli, Hy. asiaticum & {$[65,66]$} \\
\hline
\end{tabular}

N: not reported in China; B: Babesia; R: Rhipicephalus; H: Haemaphysalis; Hy: Hyalomma; I: Ixodes; D: Dermacentor

a $B$. divergens and $B$. occultans have not been reported infecting cattle in China 
Also, the presence of native bovid species, such as yaks (Bos mutus and Bos grunniens for wild and domestic yaks, respectively), may play an important role in the dynamics of $\mathrm{BB}$ in China. A recent study showed that yaks might be at high risk for infestation with ticks competent for the transmission of Babesia spp. It has also been reported that $B$. bovis, $B$. bigemina, $B$. ovata, and $B$. venatorum are spreading in the white yak populations, posing an additional threat to this already endangered bovine species [3, 9]. Also, climate changes may broaden the habitat of ticks competent to transmit Babesia spp., therefore affecting the indigenous populations of white yaks.

In summary, although $B$. bovis and B. bigemina are the most widespread species in cattle, water buffalo, and yaks in China, followed by B. orientalis, B. major, B. ovata, and $B$. U sp. Kashi (based on the data collected in this review), there is a remarkable diversity of Babesia spp. and competent ticks circulating in the country. In addition, crossspecies infections, such as the case of the sheep parasite B. motasi in cattle, suggest the presence of a complicated and unique scenario.

$\mathrm{BB}$ is a complex and difficult disease to control even in usual situations involving a few parasite species and their respective competent tick vectors. Circumstances in China are complex in terms of the Babesia species, ticks, and vertebrate hosts involved, and need to be considered if implementation of control strategies, such as vaccination, anti-Babesia drugs, and acaricides are to be effective.

\section{Risk factors}

Intrinsic risk factors associated with $\mathrm{BB}$ include animal age, nutrition and general sanitary conditions, use of vaccines and babesicidal drugs, breed of the animals, potential for infestation by tick species circulating in the study area, and the existence of preventive measures against ticks [67]. The impact of animal age is very important, given the increased resistance of young calves to acute disease [71]. The nutritional status and general well-being of the animals are obvious risk factors, with well-fed animals having an advantage and better chances to survive the impact of acute BB than emaciated and malnourished cattle [67]. Cattle breed is also considered a risk factor, since Bos taurus breeds are remarkably more susceptible to Babesia infections compared to Bos indicus cattle $[72,73]$. The latter species also have increased resistance to tick infestation. This is likely the result of long-term selection due to the evolutionary history of the native Bos indicus breeds that co-evolved with ticks and tick-borne parasites. Management practices play an important role, and systems that favor close proximity of animals may pose increased risk to tick infestation and tick-borne diseases. On the other hand, extrinsic factors that may increase the severity of the situation include other and often uncontrollable players, such as climate, animal movement, and human activities [28]. Together, worldwide climate change and globalization-related practices have resulted in a fast expansion of favorable habitat for the development of ticks and tick-borne diseases, such as BB. In addition, increased industrialization, human encroachment, and invasion of natural habitats have resulted in displacement of wild and domestic animals. It is predicted that all these risk factors mentioned above may play a role in $\mathrm{BB}$ in China and represent potential areas where more research is needed to develop efficient strategies to control the disease.

\section{Critical knowledge gaps}

Considering the increased demand for animal protein and that $\mathrm{BB}$ is currently a potential threat to the cattle industry in China [17], as it is for Babesia-endemic countries in Africa, the Americas, and Australia [18, 67, 74-77], it is critical to have a plan to evaluate impact and to control the disease. To this end, it is necessary to fill critical knowledge gaps and find appropriate answers to some important questions related to this economically important disease. These include gaps in the dynamics of BB in China, whether the risks for cattle populations are increasing or decreasing in the country, whether the disease is confined to specific location or provinces, or whether it has the potential to expand geographically, among many regions, and the impact of possible wildlife reservoirs. Importantly, regions in the country with enzootic stability versus instability need to be assessed. Considering that only a few studies have addressed these issues so far, the overall impact of BB in China is currently unknown. Important issues that need to be considered in this assessment include understanding how environmental changes and human interventions are affecting populations of Babesia-competent tick vectors, and what measures would be required to mitigate the effect of Babesia on the production of cattle milk and meat in China. A complete survey on the Babesia spp. that infect and cause clinical disease in China should be performed. This includes the recently identified Babesia sp. Mymensingh that can cause clinical babesiosis and was found endemic for cattle and water buffalo in Asia, Africa and South America. The presence of this and other Babesia species of cattle and buffalo in China should be also investigated [78]. Chief among such possible measures is the design of a proper, environmentally safe, and efficient strategy aimed at controlling ticks using acaricides, developing or improving current anti-tick vaccines [79-81], or pasture management, among other possibilities [82]. 


\section{Prospective research needs}

As successfully demonstrated by the tick control campaign in the US, which extended for about four decades $[83,84]$, control of babesiosis can be achieved by targeting ticks with acaricides [83]. However, this success was not reproduced elsewhere, and the extensive use of acaricides may be detrimental to the environment. Other environmentally-friendly measures for tick control, such as anti-tick vaccines and natural repellents, could also be considered as sustainable options [85-90]. Control of $\mathrm{BB}$ is a difficult task due to the paucity of efficient drugs and vaccines, and also to the fact that the causative agent is diverse and widespread in the environment. Regarding BB research in China from the last decades, numerous studies have been performed, and consequently new information on the life cycle of different parasite species isolated from different stages of tick vectors has been revealed [16, 26, 30]. Importantly, major progress has also been made recently in the establishment of in vitro cultivation of Babesia parasites, epidemiology surveys based on molecular and serological diagnostic methods, and screening of diagnostic and vaccine antigens $[11,15$, 20, 91, 92]. Despite these advances, no commercial diagnostic kit or vaccines are currently available in China. In most endemic areas in the world, immunologically naïve imported animals usually succumb to acute babesiosis [93]. Live vaccines, based on native Babesia strains, may be useful to protect imported Babesia naïve cattle that could be used to improve productivity in China. In addition, in the absence of alternative preventive strategies, live vaccines combined with diagnostic surveys may contribute to alleviating the burden of disease in endemic areas whenever they become enzootically unstable [81, 94].

It is well-accepted that $\mathrm{BB}$ causes enormous economic loss in endemic areas [95]; however, the exact global economic impact remains unknown, and this is especially true in China. Thus, as a first step to address the situation, commercial diagnostic kits are urgently needed to perform epidemic surveys of babesiosis in the bovid populations of China. Such surveys are essential to inform whether a certain region is endemic or free of Babesia spp. Diagnostic surveys will also determine if enzootically stable and unstable regions are present in the country $[96,97]$. Importantly, once enough epidemiological information is available, design of control plans may be aided by developing predictive models which may address the potential for expansion of the tick vectors into endangered areas [98]. For instance, epidemiological surveys could indicate the need for vaccination in enzootically unstable regions in China, by increasing the numbers of Babesia-immune animals in at-risk herds. However, exposure of cattle to the parasite in Babesia endemic areas should ideally occur at an early age (<1-year-old), since younger animals are highly resistant to the infection and develop only mild signs of acute babesiosis. In contrast, older naïve animals (>1-year-old) usually succumb to acute infection. In addition, this also applies to live vaccines based on attenuated parasites, which can only be administered to young animals (<1-year-old).

As mentioned, B. bovis and B. bigemina are the most virulent and prevalent species in endemic regions worldwide. While B. bovis causes more dramatic acute disease due to its ability to sequester in several tissues, including brain vascular epithelia causing cerebral babesiosis [94], B. bigemina is characterized by acute hemolytic anemia that may result in kidney damage and organ failure. The relative virulence of additional Babesia spp. described above remains uncertain and needs to be investigated. In addition, the presence of Babesia parasites, albeit of low virulence, may pose an important risk when animals undergo stress, immunosuppression, or co-infections with other agents. In these circumstances, clinical disease leading to death may manifest. Finally, if these "lowly virulent" parasites cause persistent infection and remain in circulation, they can be transmitted by competent ticks to other susceptible animals. It may be important to determine whether these alternative and poorly virulent parasites are present in China and whether control measures are needed.

There is a clear need to screen and identify novel Babesia targets to design and develop effective drugs for endemic areas worldwide, including China. Diminazene aceturate and imidocarb dipropionate are usually recommended and are very useful drugs for babesiosis, but they may not fully eliminate the parasites from the infected host [95]. Therefore, new vaccine strategies are also required for the implementation of efficient strategies to control and eradicate Babesia spp. A possibility is the use of gene manipulation in cultured attenuated parasites to develop better defined and non-transmissible live vaccines $[67,94]$. Another strategy is to develop subunit vaccines based on multiple essential antigens including both asexual and sexual stages of the parasite [94]. Future studies should focus on parasite-tick-host interactions, parasite metabolisms, and potential reasons that Babesia can only survive inside erythrocytes. It has been well established that erythrocytes lack immune receptors, such as $\mathrm{MHC}$, and provide a safe environment for the parasites to evade the vertebrate host immune system [99, 100]. Understanding the mechanisms of erythrocyte invasion and parasite biology inside of erythrocytes should reveal new ideas for controlling the disease, allowing the design of novel pan-babesicidal drugs and effective vaccines. Collectively, by addressing these gaps and considering all the complex cultural 
factors present in China, including the consumption of specific beef-based food and the predicted increase demand of animals that follows economic growth, among other aspects, efficient strategies to evaluate the impact of $\mathrm{BB}$ in the country would be an advantage to cattle production.

\section{Conclusions}

BB is a significant limiting and neglected factor for the development of the cattle industry in China. There is still much to be learned on parasite diversity and the dynamics of the disease in the country before methods of control can be applied effectively. One first step is the development of large-scale surveys and the identification of possible natural reservoirs that can play a role in the dynamics and expansion of the disease in the country. Development of efficient, simple diagnostic tools are prerequisite steps required for relevant epidemiological survey studies. Also, live attenuated vaccines based on local parasite isolates may be required to control outbreaks in enzootically unstable regions. Additionally, subunit vaccines that are shown to be efficacious against circulating Babesia species and isolates might be needed. These will require a better understanding of the biology of the parasite, its interactions with vertebrate and arthropod hosts, and the interactions occurring among farm and wild animals that may act as reservoirs. Other factors that directly or indirectly affect the manifestation of the disease may also need to be better understood, such as environmental and climate factors. Geographic and epidemiological data can also be used for developing predictive models for the expansion of the vector ticks [98]. More investments in basic and applied research of the disease are urgently required to attack this problem rationally. As for the current impact of BB in China, it may be necessary to bring together teams of government officials, economists, scientists, cattle industry stakeholders, and other important actors, to develop a comprehensive epidemiological analysis, followed by the design of comprehensive strategies against BB in China. This approach can potentially reveal the full impact of the disease and provide an efficient platform to deliver stable and reliable sources of food to provide for the needs of an increasing and more demanding Chinese and worldwide population.

\footnotetext{
Abbreviations

BB: Bovine babesiosis; R. microplus: Rhipicephalus microplus; R. haemaphysaloides: Rhipicephalus haemaphysaloides; H. longicornis: Haemaphysalis longicornis; H. punctata: Haemaphysalis punctata; Hy. anatolicum: Hyalomma anatolicum; Hy. asiaticum: Hyalomma asiaticum; Hy. detritum: Hyalomma detritum; Hy. rufipes: Hyalomma rufipes; I. persulcatus: Ixodes persulcatus; I. ovatus: Ixodes ovatus; D. nuttalli: Dermacentor nuttalli.
}

\section{Acknowledgements}

The authors are thankful to all the researchers whose studies have been reviewed in this manuscript. We deeply thank Jacob M. Laughery for reviewing the English and scientific aspects of the manuscript.

\section{Authors' contributions}

$\mathrm{LH}, \mathrm{RGB}$, and CES conceptualized and wrote the first draft of the manuscript. All the authors revised and approved the manuscript. YS prepared data about ticks, Figs. 1 and 2. GH wrote the section about cattle and water buffalo industries in China. GG and JLZ prepared and collected parasites pictures in the historical knowledge of bovine babesiosis in China, especially B. ovata, $B$. major, B. U sp. Kashi, and B. orientalis. All authors read and approved the final manuscript.

\section{Funding}

This study was supported by the National Key Research and Development Program of China (Grant No. 2017YFD0501200) and the National Natural Science Foundation of China (Grant Nos. 31930108 and 31772729). This work was also supported by the United States Department of AgricultureAgriculture Research Service-Current Research Information System Project No. 2090-32000-039-00D, the USDA National Institute of Food and Agriculture (Award Number: 2020-67015-31809; Proposal Number: 2019-05375, Accession Number: 1022541) and the Fundamental Research Funds for the Central Universities, China (Grant No. 2662019PY001).

Availability of data and materials

Not applicable.

\section{Declarations}

Ethics approval and consent to participate

Not applicable.

\section{Consent for publication}

Not applicable.

\section{Competing interests}

The authors declare that they have no conflicts of interest.

\section{Author details}

'State Key Laboratory of Agricultural Microbiology, College of Veterinary Medicine, Huazhong Agricultural University, Wuhan 430070, Hubei, China. ${ }^{2}$ Department of Veterinary Microbiology and Pathology, College of Veterinary Medicine, Washington State University, Pullman, WA 99164, USA. ${ }^{3}$ State Key Laboratory of Plateau Ecology and Agriculture, College of Agriculture and Animal Husbandry, Qinghai University, Xining 810016, People's Republic of China. ${ }^{4}$ Key Lab of Agricultural Animal Genetics, Breeding and Reproduction of Ministry of Education, International Joint Research Centre for Animal Genetics, Breeding and Reproduction, College of Animal Science \& Technology, Huazhong Agriculture University, Wuhan, Hubei, China. ${ }^{5}$ State Key Laboratory of Veterinary Etiological Biology, Key Laboratory of Veterinary Parasitology of Gansu Province, Lanzhou Veterinary Research Institute, Chinese Academy of Agricultural Sciences, Xujiaping, Lanzhou 730046, China. ${ }^{6}$ Animal Disease Research Unit, United States Department of Agricultural - Agricultural Research Service, Pullman, WA 99164, USA.

Received: 18 May 2021 Accepted: 11 August 2021

Published online: 07 September 2021

References

1. Babes V. Sur l'hemoglobinurie bacterienne du boeuf. Compt Rend Acad Sci Ser III Sci Vie. 1888;107:692-4

2. McCosker PJ, Ristic M, Kreier J. Babesiosis: the global importance of babesiosis. Chapter 2. Cambridge: Academic Press; 1981. p. 2-24.

3. Liu J, Guan G, Li Y, Liu A, Luo J, Yin H. A molecular survey of Babesia species and detection of a new Babesia species by DNA related to $B$. venatorum from white yaks in Tianzhu, China. Front Microbiol. 2017;8:419. 
4. Luo J, Yin H, Guan G, Zhang Q, Lu W. Description of a new Babesia sp. infective for cattle in China. Parasitol Res. 2002;88:S13-5.

5. Du C, Deng T, Zhou Y, Ye T, Zhou Z, Zhang S, et al. Systematic analyses for candidate genes of milk production traits in water buffalo (Bubalus Bubalis). Anim Genet. 2019:50:207-16.

6. Zhong J, Chen Z, Zhao S, Xiao Y. Classification of ecological types of the Chinese yak. Acta Ecol Sin. 2006;26:2068-72.

7. Wang Z. Effect of different feeding and grazing ways on continuous yield of reproductive cows of Tianzhu white yak. China Cattle Sci. 2019:45:20-1

8. Qin $S Y$, Zhang $X X$, Zhao GH, Zhou DH, Yin MY, Zhao Q, et al. First report of Cryptosporidium spp. in white yaks in China. Parasit Vectors. 2014;7:230

9. Qin SY, Wang JL, Ning HR, Tan QD, Yin MY, Zhang XX, et al. First report of Babesia bigemina infection in white yaks in China. Acta Trop. 2015:145:52-4

10. Wang C: Bovine piroplasmosis. In: The diseases of Domestic Animals in China: Ministry of Agriculture, Academic Press. 1993:381-90.

11. Sun M, Guan G, Liu Z, Wang J, Wang D, Wang S, et al. Molecular survey and genetic diversity of Babesia spp. and Theileria spp. in cattle in Gansu province China. Acta Parasitol. 2020;65:422-9.

12. Wang S. Epidemiological investigation of Babesia bigemina in yak. Sichuan Anim Husbandry Vet Med. 1989:23-4.

13. Yu J, Wang X, Wang S, Yu Q, Zhang C. Investigation of yak Babesia bigemina. Chin Yak. 1989;01:40-2.

14. Yang C, Liu J, Li A, Li Y, Liu A, Xie J, et al. Evaluating the Babesia bovis infection of cattle in China with enzyme-linked immunosorbent assay (ELISA). Acta Parasitol. 2015;60:721-6.

15. Niu Q, Liu Z, Yu P, Yang J, Abdallah MO, Guan G, et al. Genetic characterization and molecular survey of Babesia bovis, Babesia bigemina and Babesia ovata in cattle, dairy cattle and yaks in China. Parasites Vectors. 2015;8:518

16. Lv W, Yin H, Yu F, Lv W, Zhang Q, Dou H. Study on the transmission ability of Boophilus microplus against Babesia bovis and Babesia bigemina. Chin J Vet Sci Technol. 1989;7:11-2.

17. Yin H, Lu W, Luo J. Babesiosis in China. Trop Anim Health Prod. 1997;29:S11-5.

18. Bock R, Jackson L, de Vos A, Jorgensen W. Babesiosis of cattle. Parasitology. 2004;129:S247-69.

19. Lv W, Lu W, Zhang Q, Luo J, Yin H, Dou H. Survey of the species of tick-borne hacmoprotozoan of cattle and feature in China. Chin J Vet Sci Technol. 1995;25:13-6.

20. He L, Liu Q, Yao B, Zhou Y, Hu M, Fang R, et al. A historical overview of research on Babesia orientalis, a protozoan parasite infecting water buffalo. Front Microbiol. 2017;8:1323.

21. Chen SR, Yang J, Han CQ, Li HM, Wu HF. Babesiosis of buffalo caused by a combination of Babesia bigemina and B. bovis. Hubei J Anim Vet Sci. 1984;8:23-4.

22. Liu Z, Ma L, Yao B, Zhao J. The test of infected cattle by bite with tick Rhipicephalus haemaphysaloides haemaphysaloides and injection with parasitized blood of buffalo with babesiosis. Acta Vet Zootech Sinica. 1995;26:468-72.

23. Liu ZL, Zhao JL, Ma LH, Yao BA. Babesia orientalis sp. nov. parasitized in buffalo Bubalus bubalis in China (Piroplasmida: Babesiidae). Chin J Anim Vet Sci. 1997:01:85-6.

24. Liu Z, Ma L, Zhang G, Gao X. An investigation of babesiosis in buffaloes in Hubei province. Acta Vet Zootech Sinica. 1986;17:49-54.

25. Zhao J, Liu Z. Studies on the in vitro cultivation of Babesia bovis from buffalo using the blood of cattle. J Huazhong Agric Univ. 1994:013:278-80

26. Ma L, Liu Z, Zhao J. An investigation of babesiosis in Hubei province 5. The experimental demonstration of the transovarian transmission of Babesia bovis by Rhipicephalus haemaphysaloides haemaphysaloides. Chin J Anim Vet Sci. 1989:20:67-70.

27. Ma LH, Liu ZL, Zhao JL. An investigation of water buffalo babesiosis in Hubei province V. adult Rhipicephalus haemaphysaloides transmits the parasites transovarially. Chin J Anim Vet Sci. 1989;1:67-70.

28. He L, Zhou YQ, Oosthuizen MC, Zhao JL. Loop-mediated isothermal amplification (LAMP) detection of Babesia orientalis in water buffalo (Bubalus bubalis, Linnaeus, 1758) in China. Vet Parasitol. $2009 \cdot 165 \cdot 36-40$.
29. Lv W, Yin H, Lu W, Yu F, Zhao O, Dou H. Discovery of Babesia major from cattle and confirmation of its transmitting vector tick in China. Chin J Vet Sci Technol. 1988:12:11-4.

30. Lv W, Yin H, Lv W, Zhang Q, Yu F, Dou H. Experimental study on translocation of Haemaphysalis longicornis to Babesia major. Chin J Vet Sci Technol. 1990;6:5-6.

31. Bai Q, Liu G. Studies on isolation and preservation of a single species of haemotecytozoon in bovine: isolation and cryopreservation of Babesia ovata in China. Chin J Vet Med. 1990:16:2-4.

32. Bai Q, Liu G, Han G, Hui Y. Isolation and complementary transmission of Babesia ovata in Zhangjiachuan of Gansu province. Chin J Vet Sci Technol. 1994;24:9-10.

33. Yin $\mathrm{H}, \mathrm{Lv}$ W. Experimental transmission of some bovine and ovine tick borne haemoprotozoans in Gansu province. Chin J Vet Parasitol. 2000;8:17-9.

34. Liu JL, Yin H, Liu GY, Guan GQ, Ma ML, Liu AH, et al. Discrimination of Babesia major and Babesia ovata based on ITS1-58S-ITS2 region sequences of rRNA gene. Parasitol Res. 2008;102:709-13.

35. Lv W, Lv W, Zhang Q, Dou H, Yin H, Luo J, et al. Investigations on tickborne blood protozoa and characteristics of their distribution in Gansu. Chin J Vet Sci Technol. 1992;22:13-5.

36. Bai Q, Liu G, Zhang L, Zhou J. Discovery and isolation of Babesia ovata in China (in Chinese). Chin J Vet Sci Technol. 1990;12:2-4.

37. Higuchi S, Bai Q, Liu D, Wang X, Yan Z. Studies on Babesia sp. isolated from cattle in Henan. China Bull Vet Coll PLA. 1991;11:63-7.

38. Morzaria SP, Brocklesby DW, Harradine DL. Experimental transmission of Babesia major by Haemaphysalis punctata. Res Vet Sci. 1977:23:261-2.

39. Minami T, Ishihara T. Babesia ovata sp. n. isolated from cattle in Japan. Natl Inst Anim Health Q. 1980;20:101-13.

40. Yin H, Lu W, Luo J, Zhang Q, Lu W, Dou H. Experiments on the transmission of Babesia major and Babesia bigemina by Haemaphysalis punctata. Vet Parasitol. 1996;67:89-98.

41. Luo JX, Yin H, Guan GQ, Yang DY, Liu AH, Ma ML, et al. A comparison of small-subunit ribosomal RNA gene sequences of bovine Babesia species transmitted by Haemaphysalis spp. in China. Parasitol Res. 2005:95:145-9.

42. Bai Q, Liu G, Zhang L, Zhou J. Studies on isolation and preservation of a single species of haematocytozoon in bovine-experiments on the transmission of Babesia ovata. Acta Vet Zootech Sinica. 1992;2:166-71.

43. Luo JX, Chen FY, Lu WS, Guan GQ, Ma ML, Yin H. Experimental transmission of an unnamed bovine Babesia by Hyalomma spp., Haemaphysalis longicornis and Boophilus microplus. Vet Parasitol. 2003;116:115-24.

44. Luo J, Yin H, Liu Z, Yang D, Guan G, Liu A, et al. Molecular phylogenetic studies on an unnamed bovine Babesia sp. based on small subunit ribosomal RNA gene sequences. Vet Parasitol. 2005;133:1-6.

45. Chaudhri RP, Gill BS, Khan MH. Studies on transmission of Babesia bigemina. Ann Soc Belg Med Trop. 1975;55:327-32.

46. Gray JS, De Vos AJ. Studies on a bovine Babesia transmitted by Hyalomma marginatum rufipes Koch, 1844. Onderstepoort J Vet Res. 1981;48:215-23.

47. Chen D. Investigations on ovine piroplasmosis. Chin JVet Sci Technol. 1982;3:31-2.

48. Zhao X, Li C, Min Y. Investigations on ovine babesiosis. Chin J Vet Sci Technol. 1986;1:26-7.

49. Yin H, Lu W, Luo J, Zhang Q, Lu W, Dou H. Isolation and morphological observation of Babesia motasi and Babesia ovis in China. Chin J Vet Sci Technol. 1997;10:7-9

50. Lian C, He H, Bai Q, Han G, Liu G. A large new Babesia sp. found from infected sheep in China (In Chinese). Chin J Vet Sci. 1997;31:239-43.

51. Bai Q, Liu G, Liu D, Ren J, Li X. Isolation and preliminary characterization of a large Babesia sp. from sheep and goats in the eastern part of Gansu province, China. Parasitol Res. 2002;88:S16-21.

52. Liu AH, Yin H, Guan GQ, Schnittger L, Liu ZJ, Ma ML, et al. At least two genetically distinct large Babesia species infective to sheep and goats in China. Vet Parasitol. 2007;147:246-51.

53. Niu QL, Luo JX, Guan GQ, Liu ZJ, Ma ML, Liu AH, et al. Differentiation of two ovine Babesia based on the ribosomal DNA internal transcribed spacer (ITS) sequences. Exp Parasitol. 2009;121:64-8.

54. Guan GQ, Yin H, Luo JX, Lu WS, Zhang QC, Gao YL, et al. Transmission of Babesia sp to sheep with field-collected Haemaphysalis qinghaiensis. Parasitol Res. 2002;88:S22-4. 
55. Guan GQ, Moreau E, Liu JL, Hao XF, Ma ML, Luo JX, et al. Babesia sp. BQ1 (Lintan): Molecular evidence of experimental transmission to sheep by Haemaphysalis qinghaiensis and Haemaphysalis longicornis. Parasitol Int. 2010;59:265-7.

56. Herwaldt BL, Caccio S, Gherlinzoni F, Aspock H, Slemenda SB, Piccaluga $P$, et al. Molecular characterization of a non-Babesia divergens organism causing zoonotic babesiosis in Europe. Emerg Infect Dis. 2003;9:942-8.

57. Andersson MO, Bergvall UA, Chirico J, Christensson M, Lindgren PE, Nordstrom J, et al. Molecular detection of Babesia capreoli and Babesia venatorum in wild Swedish roe deer, Capreolus capreolus. Parasites Vectors. 2016;9:221.

58. Sun Y, Li SG, Jiang JF, Wang X, Zhang Y, Wang H, et al. Babesia venatorum infection in child. China Emerg Infect Dis. 2014;20:896-7.

59. Jiang JF, Zheng YC, Jiang RR, Li H, Huo QB, Jiang BG, et al. Epidemiological, clinical, and laboratory characteristics of 48 cases of "Babesia venatorum" infection in China: a descriptive study. Lancet Infect Dis. 2015;15:196-203.

60. Karnath C, Obiegala A, Speck S, Essbauer S, Derschum H, Scholz H, et al. Detection of Babesia venatorum, Anaplasma phagocytophilum and Candidatus Neoehrlichia mikurensis in Ixodes persulcatus ticks from Mongolia. Ticks Tick Borne Dis. 2016;7:357-60.

61. Qi CH, Zhou D, Liu JZ, Cheng ZQ, Zhang L, Wang L, et al. Detection of Babesia divergens using molecular methods in anemic patients in Shandong province, China. Parasitol Res. 2011;109:241-5.

62. Wang J, Zhang S, Yang J, Liu J, Zhang D, Li Y, et al. Babesia divergens in human in Gansu province. China Emerg Microbes Infect. 2019;8:959-61.

63. Zhang G, Zheng D, Tian Y, Li S. A dataset of distribution and diversity of ticks in China. Sci Data. 2019;6:105.

64. Inokuma H, Yoshizaki Y, Shimada Y, Sakata Y, Okuda M, Onishi T. Epidemiological survey of Babesia species in Japan performed with specimens from ticks collected from dogs and detection of new Babesia DNA closely related to Babesia odocoilei and Babesia divergens DNA. J Clin Microbiol. 2003:41:3494-8.

65. Song R, Wang Q, Guo F, Liu X, Song S, Chen C, et al. Detection of Babesia spp., Theileria spp. and Anaplasma ovis in border regions, northwestern China. Transbound Emerg Dis. 2018;65:1537-44.

66. Sun M, Wang J, Liu Z, Guan G, Li Y, Liu J, et al. First molecular evidence of Babesia occultans and Theileria separata infection in ticks and sheep in China. Exp Appl Acarol. 2019;78:223-9.

67. Alvarez JA, Rojas C, Figueroa JV. An overview of current knowledge on in vitro Babesia cultivation for production of live attenuated vaccines for bovine babesiosis in Mexico. Front Vet Sci. 2020;7:364.

68. Jonsson NN, Bock RE, Jorgensen WK. Productivity and health effects of anaplasmosis and babesiosis on Bos indicus cattle and their crosses, and the effects of differing intensity of tick control in Australia. Vet Parasitol. 2008:155:1-9

69. Oliveira- Sequeira TCG, Oliveira MCS, Araujo JP, Amarante AFT. PCRbased detection of Babesia bovis and Babesia bigemina in their natural host Boophilus microplus and cattle. Int J Parasitol. 2005;35:105-11.

70. Ganzinelli S, Benitez D, Gantuya S, Guswanto A, Florin-Christensen $M$, Schnittger $L$, et al. Highly sensitive nested PCR and rapid immunochromatographic detection of Babesia bovis and Babesia bigemina infection in a cattle herd with acute clinical and fatal cases in Argentina. Transbound Emerg Dis. 2020;67:159-64.

71. Homer MJ, Aguilar-Delfin I, Telford SR 3rd, Krause PJ, Persing DH. Babesiosis. Clin Microbiol Rev. 2000;13:451-69.

72. Bock RE, de Vos AJ, Kingston TG, McLellan DJ. Effect of breed of cattle on innate resistance to infection with Babesia bovis, B bigemina and Anaplasma marginale. Aust Vet J. 1997;75:337-40.

73. Zan L. Cattle production Science, Chapter 2. Beijing : China Agriculture Press; 2017. p. 40.

74. De Vos AJ. Epidemiology and control of bovine babesiosis in South Africa. J S Afr Vet Assoc. 1979;50:357-62.

75. Montenegro-James S. Prevalence and control of babesiosis in the Americas. Mem Inst Oswaldo Cruz. 1992;87:27-36.

76. Guswanto A, Allamanda P, Mariamah ES, Sodirun S, Wibowo PE, Indrayani $L$, et al. Molecular and serological detection of bovine babesiosis in Indonesia. Parasites Vectors. 2017;10:550.
77. Gohil S, Herrmann S, Gunther S, Cooke BM. Bovine babesiosis in the 21st century: advances in biology and functional genomics. Int J Parasitol. 2013;43:125-32.

78. Sivakumar T, Tuvshintulga B, Kothalawala H, Silva SSP, Lan DTB, Long PT, et al. Host range and geographical distribution of Babesia sp. Mymensingh. Transbound Emerg Dis. 2020;67(5):2233-9.

79. Kiss T, Cadar D, Spinu M. Tick prevention at a crossroad: new and renewed solutions. Vet Parasitol. 2012;187:357-66.

80. Frisch JE. Towards a permanent solution for controlling cattle ticks. Int J Parasitol. 1999;29:57-71.

81. Florin-Christensen M, Suarez CE, Rodriguez AE, Flores DA, Schnittger L. Vaccines against bovine babesiosis: where we are now and possible roads ahead. Parasitology. 2014;141:1-30.

82. Hue T, Fontfreyde C. Development of a new approach of pasture management to control Rhipicephalus microplus infestation. Trop Anim Health Prod. 2019;51:1989-95.

83. George JE, Davey RB, Pound JM. Introduced ticks and tick-borne diseases: the threat and approaches to eradication. Vet Clin North Am Food Anim Pract. 2002;18:401-16.

84. Graham $\mathrm{OH}$, Hourrigan JL. Eradication programs for the arthropod parasites of livestock. J Med Entomol. 1977;13:629-58.

85. van Oosterwijk JG. Anti-tick and pathogen transmission blocking vaccines. Parasite Immunol. 2021;43:e12831.

86. Willadsen P. Anti-tick vaccines. Parasitology. 2004;129:S367-87.

87. Bastos RG, Suarez CE, Laughery JM, Johnson WC, Ueti MW, Knowles DP. Differential expression of three members of the multidomain adhesion CCp family in Babesia bigemina, Babesia bovis and Theileria equi. PloS ONE. 2013;8:e67765.

88. Alzan HF, Lau AO, Knowles DP, Herndon DR, Ueti MW, Scoles GA, et al. Expression of 6-Cys gene superfamily defines Babesia bovis sexual stage development within Rhipicephalus microplus. PloS ONE. 2016;11:e0163791.

89. Alzan HF, Bastos RG, Ueti MW, Laughery JM, Rathinasamy VA, Cooke BM, et al. Assessment of Babesia bovis 6cys A and 6cys B as components of transmission blocking vaccines for babesiosis. Parasites Vectors. 2021;14:1-13.

90. Silva MG, Ueti MW, Norimine J, Florin-Christensen M, Bastos RG, Goff $W L$, et al. Babesia bovis expresses Bbo-6cys-E, a member of a novel gene family that is homologous to the 6-cys family of Plasmodium. Parasitol Int. 2011;60:13-8.

91. Guan G, Ma M, Liu A, Du P, Ren Q, Li Y, et al. Continuous in vitro cultivation of a recently identified Babesia that infects small ruminants in China. Vet Parasitol. 2012;187:371-8.

92. He L, Feng HH, Zhang WJ, Zhang QL, Fang R, Wang LX, et al. Occurrence of Theileria and Babesia species in water buffalo (Bubalus bubalis, Linnaeus, 1758) in the Hubei province. South China Vet Parasitol. 2012;186:490-6.

93. Ozubek S, Bastos RG, Alzan HF, Inci A, Aktas M, Suarez CE. Bovine babesiosis in Turkey: impact, current gaps, and opportunities for intervention. Pathogens. 2020;9:1041.

94. Rathinasamy V, Poole WA, Bastos RG, Suarez CE, Cooke BM. Babesiosis vaccines: lessons learned, challenges ahead, and future glimpses. Trends Parasitol. 2019:35:622-35.

95. Mosqueda J, Olvera-Ramirez A, Aguilar-Tipacamu G, Canto GJ. Current advances in detection and treatment of babesiosis. Curr Med Chem. 2012;19:1504-18.

96. Smith RD, Evans DE, Martins JR, Cereser VH, Correa BL, Petraccia C, et al. Babesiosis (Babesia bovis) stability in unstable environments. Ann NY Acad Sci. 2000;916:510-20.

97. Jonsson NN, Bock RE, Jorgensen WK, Morton JM, Stear MJ. Is endemic stability of tick-borne disease in cattle a useful concept? Trends Parasitol. 2012;28:85-9.

98. Vollering J, Halvorsen R, Mazzoni S. The MIAmaxent R package: variable transformation and model selection for species distribution models. Ecol Evol. 2019;9:12051-68.

99. Gomes PS, Bhardwaj J, Rivera-Correa J, Freire-De-Lima CG, Morrot A. Immune escape strategies of malaria parasites. Front Microbiol. 2016;7:1617. 
100. Kurup SP, Butler NS, Harty JT. T cell-mediated immunity to malaria. Nat Rev Immunol. 2019;19:457-71

101. Bai Q, Liu G, Zhou J, Zhang L. Isolation of single species of Babesia bovis. Chin J Vet Sci Technol. 1991;1:20-1.
102. Bai Q, Yin S, Chen Z, Liu G, Zhou J. Isolation of single species of Babesia bigemina. Chin J Vet Sci Technol. 1987;9:25-7.

\section{Publisher's Note}

Springer Nature remains neutral with regard to jurisdictional claims in published maps and institutional affiliations.
Ready to submit your research? Choose BMC and benefit from:

- fast, convenient online submission

- thorough peer review by experienced researchers in your field

- rapid publication on acceptance

- support for research data, including large and complex data types

- gold Open Access which fosters wider collaboration and increased citations

- maximum visibility for your research: over $100 \mathrm{M}$ website views per year

At BMC, research is always in progress.

Learn more biomedcentral.com/submissions 